Puffelen, A.L. van, Heijmans, M.J.W.M., Rijken, M., Rutten, G.E.H.M., Nijpels, G., Schellevis, F.G. Illness perceptions and self-care behaviours in the first years of living with type 2 diabetes: does the presence of complications matter? Psychology \& Health: 2015, 30(11), 1274-1287

\begin{tabular}{|l|l|}
\hline $\begin{array}{l}\text { Postprint } \\
\text { Version }\end{array}$ & 1.0 \\
\hline Journal website & $\underline{\text { http://www.tandfonline.com/doi/pdf/10.1080/08870446.201 }}$ \\
\hline Pubmed link & $\underline{\text { ht1045511//www.nunYbi.nlm.nih.gov/pubmed/25925788 }}$ \\
\hline DOI & $10.1080 / 08870446.2015 .1045511$ \\
\hline
\end{tabular}

This is a NIVEL certified Post Print, more info at http://www.nivel.eu

\title{
Illness perceptions and self-care behaviours in the first years of living with type 2 diabetes; does the presence of complications matter?
}

\author{
ANNE L. VAN PUfFELEN ${ }^{A *}$, MONIQUE J.W.M. HeIJMANS ${ }^{\wedge}$, MIEKE RIJKEN ${ }^{\wedge}$, GUY \\ E.H.M. RUTTEN ${ }^{\mathrm{B}}$, GIEL NIJPELS ${ }^{\mathrm{C}}$, FRANÇOIS G. SCHELLEVIS ${ }^{\mathrm{A}, \mathrm{C}}$ AND ON BEHALF OF \\ THE DIACOURSE STUDY GROUP \\ ${ }^{a}$ NIVEL, The Netherlands Institute for Health Services Research, Utrecht, The \\ Netherlands; \\ b Julius Center for Health Sciences and Primary Care, University Medical Center \\ Utrecht, Utrecht, The Netherlands; \\ 'Department of General Practice \& Elderly Care Medicine, EMGO Institute for \\ Health and Care Research, VU University Medical Center, Amsterdam, The \\ Netherlands \\ "Corresponding author. Email: a.vanpuffelen@nivel.nl
}

Objective: To assess illness perceptions, self-care behaviours and their relationship in recently diagnosed type 2 diabetes mellitus (T2DM) patients with and without diabetes-related complications.

Design: Cross-sectional survey among 192 recently diagnosed T2DM patients of whom $23 \%$ reported the presence of diabetes-related complications. Illness perceptions and self-care were assessed by the Revised Illness Perception Questionnaire (IPQ-R) and the revised Summary of Diabetes Self-Care Activities (SDSCA) measure.

Results: Generally, participating patients perceived T2DM as a chronic, but relatively controllable condition with minor consequences. In the presence of complications, however, T2DM was perceived as more unpredictable with more (serious) consequences and less controllable by self-care or medical treatment. Furthermore, engagement in exercise and foot care was reported more often by patients with complications. Self-care was related to certain illness perception dimensions, and interactions between perceptions and complications were found.

Conclusion: T2DM patients in the first years of their illness are often recom- mended to make lifestyle changes in the absence of noticeable diabetes-related symptoms or complaints. As many T2DM patients do 
Puffelen, A.L. van, Heijmans, M.J.W.M., Rijken, M., Rutten, G.E.H.M., Nijpels, G., Schellevis, F.G. Illness perceptions and self-care behaviours in the first years of living with type 2 diabetes: does the presence of complications matter? Psychology \& Health: 2015, 30(11), 1274-1287

not seem to perceive their condition to be serious and postpone lifestyle changes until diabetes- related complications appear, a major challenge for professionals is to convince asymptomatic patients of the importance of self-care.

\section{INTRODUCTION}

The importance of early treatment and lifestyle changes in type 2 diabetes mellitus (T2DM) patients is widely recognised in the medical field. In order to diminish the risk of serious long-term complications, guidelines recommend that $\mathrm{T} 2 \mathrm{DM}$ patients engage in a diabetes self-care regimen (e.g. regular exercise, healthy diet, foot care and not smoking) directly after diagnosis (American Diabetes Association [ADA], 2014; Rutten et al., 2013). Since these (changes in) behaviours most often need to be performed in the absence of noticeable diabetes-related symptoms or complaints, it is imaginable that sticking to this selfmanagement regimen is challenging for many patients.

Previous research has shown that the extent to which patients adhere to diabetes self-care recommendations is strongly related to their perceptions of their illness and its treatment (Harvey \& Lawson, 2009). Illness perceptions are the central concept of the common-sense model of selfregulation of health and illness (Leventhal, Brissette, \& Leventhal, 2003; Leventhal, Nerenz, \& Steele, 1984; Leventhal, Meyer, \& Nerenz, 1980). According to this model, people hold personal beliefs about their illness which, to a large extent, determine how people respond to their condition. Illness perceptions include perceived symptoms attributed to the condition (identity), beliefs about the timeline of the condition, its consequences, perceived ability to control the condition and the extent to which the treatment is effective in controlling the condition, compre- hensibility or understanding of the condition, emotional responses and concerns regarding the condition, and beliefs on possible causes of the condition. The CSM presumes that these different beliefs correlate in a logical way and together act as a framework for coping strategies and behavioural responses of patients which, in turn, impact on their appraisal of health outcomes. Illness perceptions are constructed within the context of medical information, social communication (media, friends and family and other patients) and personal experience. As these perceptions are not static, but change over time as a result of new information and experiences (Leventhal et al., 1980; Skinner et al., 2014), it is likely that T2DM is perceived differently by recently diagnosed patients than by patients with a longer illness duration, especially considering the rather progressive nature of the illness.

Overall, recently diagnosed patients have been found to be rather optimistic about their ability to control the condition and the effectiveness of treatment strategies. In addition, they experienced the emotional impact of diabetes to be relatively low and the consequences (for daily life) as not very serious (Khunti et al., 2008; Klein Woolthuis et al., 2013; Lawson, Bundy, \& Harvey, 2008). Although these optimistic perceptions have generally been found to positively relate to self-care behaviour and glycemic con- trol (Gherman et al., 2011; Hagger \& Orbell, 2003; Harvey \& Lawson, 2009; 
Puffelen, A.L. van, Heijmans, M.J.W.M., Rijken, M., Rutten, G.E.H.M., Nijpels, G., Schellevis, F.G. Illness perceptions and self-care behaviours in the first years of living with type 2 diabetes: does the presence of complications matter? Psychology \& Health: 2015, 30(11), 1274-1287

McSharry, Moss-Morris, \& Kendrick, 2011), questions have been raised as to whether this also applies to the first years of living with T2DM. For example, Thoolen, De Ridder, Bensing, Gorter, and Rutten (2008) suggested in their review that high levels of perceived controllability and low emotional impact might rather be non-conducive than conducive to selfcare behaviours, and these (overly) optimistic perceptions might actu- ally be an indicator of patients not truly engaging in lifestyle changes and reflecting the seriousness of T2DM on their own condition.

Considering the great importance of diabetes self-care in recently diagnosed T2DM patients and the assumed key role of illness perceptions in guiding these activities, we assessed the illness perceptions, self-care behaviours and their relationship in T2DM patients during the first years of illness. As we expected that concrete experiences with diabetes will alter patients' perceptions, we explored whether the illness perceptions of T2DM patients differ by the presence or absence of diabetes-related complications. Assuming that changes in illness perceptions contribute to changes in selfcare in the presence of notable signs and symptoms, we also investigated the differences in self-care behaviours between patients with complications and patients without complications. Finally, we also studied whether illness perceptions associated differently with self-care in patients with complications, compared to patients without complications.

More precisely, our research questions were as follows: Which illness perceptions are held by diabetes patients during the first years of T2DM? Do these illness perceptions differ between patients with and without diabetesrelated complications?

Which self-care behaviours are performed during the first years of T2DM? Do these self-care behaviours differ between patients with and without diabetes- related complications?

How are illness perceptions and self-care behaviours related during the first years of T2DM? Does this relationship differ in the presence of diabetesrelated complications?

\section{Methods}

To answer our research questions, we used the baseline data from the Diacourse study. For the inclusion of patients in this study, a two-stage sampling procedure was applied. First, general practices in the north, west, south-west and centre of the Netherlands were recruited. Then, patients meeting the inclusion criteria were selected from the medical records kept in the participating general practices. All Dutch inhabitants are obligatory listed with a general practice. Criteria for patients to be included in the study were (1) being diagnosed with T2DM one to three years ago, as recorded by their GP and (2) being aged between 18 and 85 years. Patients were excluded if they (1) were not able to speak, read and/or understand the Dutch language sufficiently, (2) had insufficient mental or intellectual capacities to participate in the study, (3) were under treatment for severe psychological or psychiatric conditions and (4) were recently diagnosed with a severe or life-threatening comorbid condition (e.g. cancer and 
Puffelen, A.L. van, Heijmans, M.J.W.M., Rijken, M., Rutten, G.E.H.M., Nijpels, G., Schellevis, F.G. Illness perceptions and self-care behaviours in the first years of living with type 2 diabetes: does the presence of complications matter? Psychology \& Health: 2015, 30(11), 1274-1287

stroke), according to their GP. Selected patients received a written invitation for participation. After informed consent, participating patients filled in the baseline questionnaire. The Diacourse study was approved by the Medical Ethical Committee of the VU University Medical Center, Amsterdam.

\section{Measures}

\section{Illness perceptions}

The Revised Illness Perception Questionnaire (IPQ-R) (Moss-Morris et al., 2002) was used to assess illness perceptions. In the first section of this questionnaire, 'illness identity' was measured as the number and frequency in which symptoms are identified as part of the illness. We used the original 14-item symptom list of common symptoms (e.g. fatigue and headaches) (Moss-Morris et al., 2002) for this purpose. Patients indicated for each symptom whether they had experienced this symptom recently and whether they perceived this symptom to be related to their diabetes (yes/no). The sum of the yes-rated items on the second rating forms the illness identity subscale (range $0-14$ ). The second section of the IPQ-R contained 38 items in seven subscales: 'timeline acute/chronic' ( 6 items, e.g. 'My diabetes will last for a long time', Cronbach's $\alpha=.87$ ); 'timeline cyclical' (4 items, e.g. 'My diabetes is very unpredictable', $\alpha=.89$ ); 'consequences' (6 items, e.g. 'My diabetes is a serious condition', $\alpha=.74)$; 'personal control' (6 items, e.g. 'The course of my diabetes depends on me', $\alpha=.74)$; 'treatment control' (5 items, e.g. 'My treatment can control my diabetes', $\alpha=.56$ ); 'coherence' or understanding of T2DM (5 items, e.g. 'My diabetes doesn't make any sense to me', $\alpha=.79$ ) and 'emotional representation' ( 6 items, e.g. 'When I think about my diabetes I get upset', $\alpha=.83$ ). All items were scored on a five- point Likert scale, ranging from 1 (strongly disagree) to 5 (strongly agree). Mean subscale scores were computed by summing the items and dividing it by the number of items result- ing in a subscale score (range 1-5). Higher scores on the subscales indicated a greater perceived impact of T2DM on the patient's life (consequences) or emotional state (emotional representation), a more chronic timeline perception (timeline acute/chronic), a stronger belief in an unpredictable course (timeline cyclical), a stronger belief in controllability of the illness either by self-care (personal control) or professional treatment (treatment control) and a better understanding of T2DM and its treatment (coherence).

In the third section, patients' causal beliefs (18 items) were measured, using the same Likert-type scale as in section two. Based on suggestions of MossMorris et al. (2002) and an exploratory factor analysis, we constructed two scales: one scale repre- senting beliefs about psychological factors as a cause of T2DM (6 items: 'Stress or worry', 'My mental attitude', 'Family problems or worries', 'Overwork', 'My emotional state', and 'My personality'; $\alpha=.84$ ) and one scale representing own (risky) behaviour in the past as a causal factor ( 5 items: 'Diet or eating habits', 'Poor medical care in my past', 'My own behaviour', 'Smoking', and 'Alcohol'; $\alpha=.72$ ). For these two sub- scales, mean scores were computed, ranging from 1 to 5, with higher scores being indicative of a stronger belief in a certain cause. 
Puffelen, A.L. van, Heijmans, M.J.W.M., Rijken, M., Rutten, G.E.H.M., Nijpels, G., Schellevis, F.G. Illness perceptions and self-care behaviours in the first years of living with type 2 diabetes: does the presence of complications matter? Psychology \& Health: 2015, 30(11), 1274-1287

The single item 'My diabetes was caused by chance or bad luck' was treated as a third causal factor (range 1-5).

\section{Self-care}

Self-care was measured by the Dutch version of the revised Summary of Diabetes Self-Care Activities (SDSCA) measure (Toobert, Hampson, \& Glasgow, 2000). This questionnaire measured six aspects of the diabetes regimen: exercise ( 2 items; $\alpha=.76$ ), glucose monitoring ( 2 items, $\alpha=.64$ ), foot care ( 2 items; $\alpha=.70$ ), general diet ( 2 items; $\alpha=.82$ ), specific diet (2 items, $\alpha=.02$ ) and smoking ( 1 item). Respondents reported the frequency (days per week) these various activities were performed in the previous 7 days. The two items measuring the specific diet subscale were analysed separately, because of their low internal consistency, as was also suggested by Toobert et al. (2000). Furthermore, the subscale assessing bloodglucose monitoring was left out in this study, since this aspect of self-care is not part of the diabetes care regimen in the majority of the (recently diagnosed) Dutch T2DM patients (Eerste Associatie van Diabetes Verpleegkundigen [EADV], 2012).

\section{Complications}

To assess diabetes-related microvascular complications, patients were asked to indicate whether they suffered from (1) eye problems: retina problems (retinopathy), (2) kidney problems: proteinuria or dialysis (nephropathy), (3) nerve damage (neuropathy) and (4) foot problems (need for adapted shoes, wounds and amputation). Complications were summed and dichotomised into 'complications absent'(0) and 'one or more complications present' (1).

\section{Background variables}

We included a number of socio-demographic and illness-related characteristics in this study to describe our sample and to adjust for in the multivariate analyses. Apart from age and gender, which were derived from the GP records, self-reported level of educa- tion and marital status was included. Level of education was categorised into low (no education, primary school or low vocational training), middle (high school or middle vocational training) and high (college or university) based on the reported highest type of education completed. Marital status was dichotomised into 'married or cohabiting' and 'other' (single, divorced and widowed). Diabetes duration was also derived from the GP records. Type of diabetes treatment was self-reported by patients and categorised into (1) lifestyle advice only, (2) oral hypoglycaemic agents and (3) insulin injections. For the multivariate analyses, treatment was dichotomised into nonpharmacological treatment (lifestyle advice only) and pharmacological treatment (oral hypoglycaemic agents, insulin injections). The presence of comorbidity was assessed by asking patients to indicate whether they suffered from (1) heart and vessel disease (e.g. serious heart condition or infarction), (2) cancer, (3) respiratory problems (asthma and COPD), (4) 
Puffelen, A.L. van, Heijmans, M.J.W.M., Rijken, M., Rutten, G.E.H.M., Nijpels, G., Schellevis, F.G. Illness perceptions and self-care behaviours in the first years of living with type 2 diabetes: does the presence of complications matter? Psychology \& Health: 2015, 30(11), 1274-1287

joint conditions (neck and back problems, osteoporosis and arthritis) or (5) 'other' and dichotomised into no comorbidity (0) vs. comorbidity (1).

\section{Data analysis}

Population characteristics are reported for the total sample and for patients with and without diabetes-related complications separately. Intercorrelations between the IPQ-R subscales for patients with and without complications were calculated to explore whether illness perceptions correlate in a comparable way in both groups. Chi-square and independent samples t-tests were used to test the differences between patients with or without complications on illness perceptions and self-care behaviours. Linear regression analyses were conducted to analyse the independent effect of illness perceptions (model 2) and the presence of complications (model 3) on self-care behaviours, (exercise, foot care, general and specific diet), adjusted for age, gender, comorbidity, type of treatment and diabetes duration (model 1). For smoking, a logistic regression analysis was performed in the same manner. Moderation between complications and illness perceptions was determined by conducting regression analy- ses for each illness perception subscale separately, estimating the main effects of the illness perception dimensions and complications together with their interaction effect (model 2) on self-care, adjusted for the aforementioned demographic and illness-related characteristics (model 1). All variables in the regression and moderation analyses were centred, following the guidelines described by Kraemer and Blasey (2004). Statistical significance was set at $\mathrm{p}<.05$.

\section{RESULTS}

\section{Study population characteristics}

In total, 195 patients participated in the study. Three patients had a diabetes duration of four years or more at the time of the measurement and were therefore excluded. The socio-demographic and illness-related characteristics of the remaining 192 patients are shown in Table 1. Of five participants, it was not known whether they had diabetes- related complications or not. These participants were therefore included in the total group results, but not in the subgroup analyses.

The mean age of the participating patients was 64.3 years (range 27.0-84.2), and the mean diabetes duration was 2.3 years (range 1.0-3.8). The majority of the patients $(68.4 \%)$ reported to use oral hypoglycaemic agents (or insulin) to treat their diabetes. More than one-fifth of the participants $(22.5 \%)$ reported the presence of one or more diabetes-related complications or complaints, with foot problems $(10.2 \%)$ and eye problems $(8.6 \%)$ being the most frequently reported. Two-thirds $(66.3 \%)$ of the participants reported the presence of one or more comorbid conditions, with joint problems being the most prevalent (35.3\%). Patients with complications significantly differed from patients without complications regarding diabetes duration and rates of self-reported comorbid conditions. 
Puffelen, A.L. van, Heijmans, M.J.W.M., Rijken, M., Rutten, G.E.H.M., Nijpels, G., Schellevis, F.G. Illness perceptions and self-care behaviours in the first years of living with type 2 diabetes: does the presence of complications matter? Psychology \& Health: 2015, 30(11), 1274-1287

\section{Illness perceptions}

Mean scores on the illness perception dimensions are depicted in Table 2. The majority of the patients did not experience complaints that they attributed to (their) diabetes (71.4\%). Twenty per cent attributed one or two complaints to their diabetes and the remaining eight per cent attributed three or more complaints to diabetes (range 3-8). The most frequently reported complaint attributed to T2DM was fatigue $(16.4 \%)$, followed by sensitive eyes $(9.5 \%)$, stiff joints $(6.9 \%)$ and dizziness $(6.9 \%)$.

\section{[TABLE 1] [TABLE 2]}

The scores on the different illness perception dimensions indicated that, in general, patients perceived their illness as chronic but not very serious, with a low (emotional) impact on their daily life and well controllable either by self-care or medical treatment. Considering patients' ideas about the causes of their diabetes, patients predominantly thought that their diabetes has been caused by fate, followed by their own behaviour in the past, such as dietary behaviours and smoking.

Significant differences were found between the perceptions of patients with com- plications and patients without complications. Patients with complications experienced and attributed more symptoms to their diabetes, experienced the course and symptoms of their diabetes as more unpredictable, rated the impact of their disease on their daily life and emotional state as more serious and believed less in the controllability of their illness, either by self-care or professional treatment.

As illness perception dimensions are not unrelated, but presumed to form a coherent model, we also checked the inter-correlations between the different illness perception dimensions (data not shown). The different subscales appeared to relate in a logical manner, with correlations ranging up to 63 . Overall, beliefs on the cyclical nature of the condition and its symptoms, the possibilities for control (personal and treatment control) and the comprehensibility of the condition particularly correlated strongly with all other dimensions. In patients with complications, particularly the belief that diabetes is a chronic condition that will not go away (timeline chronic) and the feeling that one does not understand the illness (coherence) correlated negatively with feelings of control. In patients without complications, the extent to which they view their illness as (un)predictable (timeline cyclical) seemed to be particularly important. Patients who experienced diabetes as a more unpredictable disease with symptoms changing from day to day, were more convinced that diabetes has serious consequences, more strongly believed in fate or stress as the cause of their diabetes and experienced less control and less understanding than patients who perceived diabetes to be more predictable.

\section{SELF-CARE BEHAVIOUR}

The extent to which T2DM patients engage in self-care behaviours is shown in Table 3. Following the recommendations for healthy eating (general diet and the recommended servings of fruit and vegetables) and non-smoking were the behaviours most often performed during the previous week. Foot 
Puffelen, A.L. van, Heijmans, M.J.W.M., Rijken, M., Rutten, G.E.H.M., Nijpels, G., Schellevis, F.G. Illness perceptions and self-care behaviours in the first years of living with type 2 diabetes: does the presence of complications matter? Psychology \& Health: 2015, 30(11), 1274-1287

care, which comprised checking one's feet and the inside of the shoes, was not commonly performed during the previous week in this recently diagnosed group. In general, self-care behaviours were performed more frequently by patients with diabetes-related complications, but only the differences in the frequency of foot care reached statistical significance.

\section{Associations between illness perceptions and self-care}

Bivariate correlations revealed significant associations between self-care behaviours and some of the illness perception dimensions, although the correlations found were gener- ally low. Physical activity and general dietary behaviours were positively associated with stronger beliefs of personal control $(\mathrm{r}=.19, \mathrm{p}<.05 ; \mathrm{r}=.23, \mathrm{p}<.01)$ and treat- ment control $(\mathrm{r}$ $=.18, \mathrm{p}<.05 ; \mathrm{r}=.25, \mathrm{p}<.01)$. Foot care was associated with more symptoms being attributed to diabetes $(\mathrm{r}=.19, \mathrm{p}<.05)$, stronger beliefs about diabetes being a chronic condition $(\mathrm{r}=.19, \mathrm{p}<.05)$ with unpredictable symptoms $(\mathrm{r}=.18, \mathrm{p}<.05)$ and feeling more emotionally upset by the illness $(\mathrm{r}=.15, \mathrm{p}<.05)$. Eating the recommended servings of fruits and vegetables was negatively associated with the belief that diabetes was caused by own (risk) behaviours in the past $(\mathrm{r}=-.23, \mathrm{p}<.01)$. Not smoking was negatively associated with perceived consequences $(\mathrm{r}=-.15$, $\mathrm{p}<.05)$ and beliefs that diabetes was caused by psychological factors $(\mathrm{r}=$ $-.15, \mathrm{p}<.05)$ or own behaviour $(\mathrm{r}=-.23, \mathrm{p}<.01)$.

\section{[TABLE 3][TABLE 4]}

Table 4 shows the results of the multivariate regression analyses to predict the dif- ferent self-care behaviours. As might be expected on the basis of the bivariate correla- tions, illness perceptions appeared to contribute minimally to the explanation of the variance in self-care behaviours. Perceived personal control was significantly positively associated with physical activity and general dietary behaviours. Indicating own past behaviours as a causal factor for diabetes was negatively associated with eating the recommended servings of fruit and vegetables and non-smoking. Perceiving T2DM to be a chronic condition was positively related to foot care. Finally, the presence of self- reported complications was found to be associated with increased physical activity and foot care, independently from illness perceptions. Moderation analyses showed that some illness perception dimensions related differently to self-care in the presence of diabetes-related complications. First, a significant interaction effect was found between complications and emotional representations on foot care $(p<.05)$, with a higher fre- quency of foot care being related to higher levels of emotional representations in patients with complications $(\beta=.36, \mathrm{p}<.01)$, but not in patients without complications $(\beta=.03, \mathrm{~ns})$. In addition, the (direction of the) association between foot care and perceptions of diabetes being caused by bad luck differed significantly $(\mathrm{p}<.05)$ between patients with complications $(\beta=.31, \mathrm{~ns})$ and patients without complications $(\beta=-.10$, $\mathrm{ns})$. Finally, an interaction was found between complications and perceived consequences on non-smoking $(\mathrm{p}<.05)$, with perceptions of diabetes 
Puffelen, A.L. van, Heijmans, M.J.W.M., Rijken, M., Rutten, G.E.H.M., Nijpels, G., Schellevis, F.G. Illness perceptions and self-care behaviours in the first years of living with type 2 diabetes: does the presence of complications matter? Psychology \& Health: 2015, 30(11), 1274-1287

having more (serious) consequences being more strongly negatively related to non-smoking in patients with complications $(\mathrm{OR}=.10, \mathrm{p}<.05)$ than in patients without complications $(\mathrm{OR}=.80, \mathrm{~ns})$.

\section{DISCUSSION}

Overall, participating T2DM patients perceived their illness as chronic but not very seri- ous, with a low (emotional) impact on their daily life and well controllable either by self-care or medical treatment. In the presence of (self-reported) complications, how- ever, T2DM was perceived as a more unpredictable illness with more consequences. In addition, patients with complications believed less in the controllability of their condi- tion by selfcare or medical treatment and also felt more emotionally upset as a result of their diabetes. These results seem to be in accordance with results of previous stud- ies, indicating the presence of mainly optimistic perceptions regarding controllability and consequences of T2DM in the first years after diagnosis (Khunti et al., 2008; Klein Woolthuis et al., 2013; Lawson et al., 2008), which appear to decrease in the presence of the diabetes-related complications (Searle et al., 2008).

Performance of self-care varied over the five different behaviours assessed. Guideli- nes for healthy food and diet were reported to be followed for about 5 days per week on average. Also, the majority of the participating patients $(82 \%)$ indicated to be a non- smoker. Exercise was reported somewhat less often: patients were physically active for less than 4.5 days per week on average, which is below the Dutch standard of healthy exercise behaviour (Kemper, Ooijendijk, \& Stiggelbout, 2000). These results partly sup- port previous studies indicating lifestyle behaviours to be particularly challenging aspects in diabetes care (Glasgow, Hampson, Strycker, \& Ruggiero, 1997; Rubin \& Peyrot, 2001; Ruggiero et al., 1997). Foot care, a self-care behaviour specifically related to diabetes, was hardly performed by the majority of the participating patients during the previous week. Contrary to expectations, only a few illness perception dimensions were associated with self-care behaviours. Patients who perceived they had the ability to control their diabetes, reported to have been more physically active and to have followed the general guidelines for healthy eating and diet more often. These findings seem to support previous studies that identified control perceptions to be particularly influential on health behaviours (Gherman et al., 2011; Harvey \& Lawson, 2009). In addition, our study showed that patients who more strongly believed their own risky behaviours in the past to have caused the onset of their diabetes were less likely to have consumed the recom- mended amounts of fruits and vegetables and more likely to have smoked during the past week. This seems to be contrary to the general belief that patients' awareness of unhealthy behaviours being a major cause for developing diabetes is an important condition for engaging in healthy behaviours later on. It should, however, be kept in mind that perceptions not only influence behaviours, but also vice versa. Patients, who have never been smoking and do not perceive their dietary behaviours prior to diagnosis as unhealthy, will most likely not identify 'own risky behaviours' as a cause for their diabetes. 
Puffelen, A.L. van, Heijmans, M.J.W.M., Rijken, M., Rutten, G.E.H.M., Nijpels, G., Schellevis, F.G. Illness perceptions and self-care behaviours in the first years of living with type 2 diabetes: does the presence of complications matter? Psychology \& Health: 2015, 30(11), 1274-1287

In addition to some of the illness perceptions dimensions, the presence of complica- tions was found to be associated with certain self-care behaviours, namely physical activity and foot care. These findings seem to partly support previous studies (Thoolen et al., 2008; Thorne, Paterson, \& Russel, 2003) suggesting that the perceived urge and need to make behavioural changes primarily appear to arise in the presence of diabetesrelated symptoms. Significant interaction effects found in this study seemed to partly support previous hypotheses on illness perceptions being related to self-care differently in the presence of diabetes-related complications or complaints. The importance of the perceived seriousness and experienced distress, resulting from diabetes-related com- plaints, for the performance of self-care appears to be supported by the finding that emotional representations were more strongly associated with checking one's feet more regularly once complications were present. On the contrary, perceptions of the serious- ness (of the consequences) of diabetes were associated more strongly with smoking in the presence of complications. However, as smoking may be part of a long existing life- style, the heightened perceived consequences are most likely the result of experiencing complications and patients' awareness of their potentially harmful smoking behaviour. The positive association between bad luck as a causal factor and foot care in patients with complications was opposite to the direction found in patients without complications, as well as the general conception that lack of awareness of own behaviours as a risk factor for diabetes negatively associates with the performance of self-care. Possibly, patients who perform foot care on a regular basis (e.g. because they are instructed to do so by their health care provider), but who also experience diabetes-related complaints might believe less in the influence of own behaviours on (the course of) their diabetes.

We believe the relatively low proportion of significant associations between illness perceptions and self-care found in this study might be explained by several factors. First, it is difficult to determine whether the self-care behaviours, with the exception of foot care, were actually performed as a part of the diabetes treatment regimen or rather as a part of an already existing lifestyle. Furthermore, the fact that we studied the effects of separate illness perception dimensions, rather than illness perception clusters, may have contributed to the relatively few associations found with self-care behaviours and lifestyle (Skinner et al., 2011); particularly considering the high perceived controllability and low perceived consequences that were generally found in this study. The low variation in self- care behaviours and illness perceptions in this group of relatively recently diagnosed T2DM patients, however, did not allow for clustering of perception dimensions.

\section{Strengths and limitations}

To our knowledge, this study is the first to examine the differences in both illness perceptions and self-care behaviours and its relationship in relatively recently diagnosed T2DM patients with and without complications. In addition, participants were recruited from a large sample of participating GPs in different regions of the Netherlands, which enhances the 
Puffelen, A.L. van, Heijmans, M.J.W.M., Rijken, M., Rutten, G.E.H.M., Nijpels, G., Schellevis, F.G. Illness perceptions and self-care behaviours in the first years of living with type 2 diabetes: does the presence of complications matter? Psychology \& Health: 2015, 30(11), 1274-1287

representativeness of the study population. However, a few factors should be kept in mind when interpreting the results. First, because of the crosssectional design, conclusions about causality cannot be drawn in this study. In addition, data on diabetes-related complications were self-reported and may not be consistent with complications from a medical point of view. It should, however, be kept in mind that perceived health and illness are often considered to be more predictive of health behaviours and outcomes than objective, medical indicators (Idler, 1992; Perrig-Chiello, Perrig, \& Stähelin, 1999).

\section{Implications}

This study provides insight into the self-care behaviours, illness perceptions and their relationship in patients in the first years of living with T2DM. The belief that diabetes is controllable by self-care seems to be an important indicator of physical activity and dietary behaviour. However, it remains unclear whether feelings of control give patients more confidence to engage in self-care behaviours or that self-care behaviours make that patients feel more in control. Reasoning from the CSM, both paths are likely and may be intertwined, as the model stresses the importance of concrete experience in forming illness perceptions and, in turn, guiding (coping) behaviours, including self-care behaviours, of individuals (Leventhal et al., 1984). Also, the results suggest that patients are more triggered to engage in certain selfcare behaviours when they experience diabetes-related complications or symptoms than when complaints are absent. Although these correlations were generally weak and the results are derived from a cross-sectional study, these findings deserve further investigation as they may have important implications for clinical practice.

Preventive action in the form of healthy behaviours is important for recently diag- nosed T2DM patients to prevent complications and to slow down disease progression. Results of this study appear to support previous studies suggesting that patients are less motivated to engage in self-care in the absence of any complaints. It is a major chal- lenge for health care providers to convince asymptomatic patients of the importance of self-care and to explain which role each of the self-care behaviours plays in the course of diabetes so that patients understand why they have to invest in self-care. For those who already experience complications, feelings of control or selfefficacy are of particular importance. Health care providers should advise and support patients, for example by providing information or teaching skills, so that patients gain the confidence to perform self-care behaviours, particularly when serious complications or comorbid conditions are present which interfere with self-care behaviours.

It would be interesting to test our findings in a longitudinal study with larger groups of patients that vary more in the presence of diabetes-related complaints and complications. Preferably, individually recommended selfcare behaviours would be the focus of the study rather than general lifestyle variables, such as healthy eating and being physically active, as was done in this study. Finally, it is important to remember that diabetes management does not only comprise self-care behaviours, but also patients' methods to adapt to living with the illness socially and emotionally. Hence, taking a 
Puffelen, A.L. van, Heijmans, M.J.W.M., Rijken, M., Rutten, G.E.H.M., Nijpels, G., Schellevis, F.G. Illness perceptions and self-care behaviours in the first years of living with type 2 diabetes: does the presence of complications matter? Psychology \& Health: 2015, 30(11), 1274-1287

broader approach of diabetes management by including psychosocial responses would be of special interest.

\section{Acknowledgements}

We would like to thank the GPs and the patients and partners who participated in this study.

\section{Disclosure statement}

No competing interests declared.

\section{Funding}

This work was supported by the Dutch Diabetes Research Foundation [grant number 2009.70.001].

\section{REFERENCES}

American Diabetes Association. (2014). Standards of medical care in diabetes 2014. Diabetes Care, 37, S14-S80.

Eerste Associatie van Diabetes Verpleegkundigen. (2012). Multidisciplinaire richtlijn overzelfcontrole van de bloedglucosewaarden door mensen met diabetes [A multidisciplinary guideline about self-monitoring of blood glucose values by people with diabetes]. Retrieved from http://www. eadv.nl/page/Richtlijnen1/Zelfcontrole-open?mod[1238][i]=57

Gherman, A., Schnur, J., Montgomery, G., Sassu, R., Veresiu, I., \& David, D. (2011). How are adherent people more likely to think? A meta-analysis of health beliefs and diabetes self-care. The Diabetes Educator, 37, 392-408.

Glasgow, R. E., Hampson, S. E., Strycker, L. A., \& Ruggiero, L. (1997). Personalmodel beliefs and social-environmental barriers related to diabetes selfmanagement. Diabetes Care, 20, 556-561.

Hagger, M. S., \& Orbell, S. (2003). A meta-analytic review of the common-sense model of illness representations. Psychology and Health, 18, 141-184.

Harvey, J. N., \& Lawson, V. L. (2009). The importance of health belief models in determining self-care behaviour in diabetes. Diabetic Medicine, 26, 5-13.

Idler, R. E. (1992). Self-assessed health and mortality: A review of studies. In S. Maes, H. Leventhal, \& M. Johnston (Eds.), International review of health psychology (pp. 33-54). New York, NY: Wiley.

Kemper, H. G. C., Ooijendijk, W. T. M., \& Stiggelbout, M. (2000). Consensus over de Nederlandse Norm voor Gezond Bewegen. Tijdschrift voor Sociale Gezondheidszorg [Consensus on the Dutch standard for healthy exercise], 78, 180-183.

Khunti, K., Skinner, T. C., Heller, S., Carey, M. E., Dallosso, H. M., \& Davies, M. J., on behalf of the DESMOND Collaborative. (2008). Biomedical, lifestyle and psychosocial characteris- tics of people newly diagnosed with type 2 diabetes: Baseline data from the DESMOND randomized controlled trial. Diabetic Medicine, 25, 1454-1461.

Klein Woolthuis, E. P., De Grauw, W. J., Cardol, M., Van Weel, C., Metsemakers, J. F., \& Biermans, M. C. (2013). Patients' and partners' illness perceptions in screen-detected versus clinically diagnosed type 2 diabetes: Partners matter! Family Practice, 30, 418-425.

Kraemer, H. C., \& Blasey, C. M. (2004). Centring in regression analyses: A strategy to prevent errors in statistical inference. International Journal of Methods in Psychiatric Research, 13, 141-151.

Lawson, V. L., Bundy, C., \& Harvey, J. N. (2008). The development of personal models of dia- betes in the first 2 years after diagnosis: A prospective longitudinal study. Diabetic Medicine, 25, 482-490. 
Puffelen, A.L. van, Heijmans, M.J.W.M., Rijken, M., Rutten, G.E.H.M., Nijpels, G., Schellevis, F.G. Illness perceptions and self-care behaviours in the first years of living with type 2 diabetes: does the presence of complications matter? Psychology \& Health: 2015, 30(11), 1274-1287

Leventhal, H., Brissette, I., \& Leventhal, E. (2003). The common-sense model of self-regulation of health and illness. In C. L. Cameron \& H. Leventhal (Eds.), The self-regulation of health and illness behaviour (pp. 42-61). London: Routledge.

Leventhal, H., Meyer, D., \& Nerenz, D. R. (1980). The common-sense representation of illness danger. In S. Rachman (Ed.), Contributions to medical psychology (pp. 7-30). New York, NY: Pergamon Press.

Leventhal, H., Nerenz, D. R., \& Steele, D. J. (1984). Illness representations and coping with health threats. In A. Baum, S. E. Taylor, \& J. E. Singer (Eds.), Handbook of psychology and health (pp. 219-252). Hillsdale, NJ: Erlbaum.

McSharry, J., Moss-Morris, R., \& Kendrick, T. (2011). Illness perceptions and glycaemic control in diabetes: A systematic review with meta-analysis. Diabetic Medicine, 28, 1300-1310.

Moss-Morris, R., Weinman, J., Petrie, K. J., Horne, R., Cameron, L. D., \& Buick, D. (2002). The revised illness perception questionnaire (IPQ-R). Psychology and Health, 17(1), 1-16.

Perrig-Chiello, P., Perrig, W. J., \& Stähelin, H. B. (1999). Health control beliefs in old age - Relationship with subjective and objective health, and health behaviour. Psychology, Health \& Medicine, 4, 83-94.

Rubin, R. R., \& Peyrot, M. (2001). Psychological issues and treatments for people with diabetes. Journal of Clinical Psychology, 57, 457-478.

Ruggiero, L., Glasgow, R. E., Dryfoos, J. M., Rossi, J. S., Prochaska, J. O., Orleans, C. T., ... Johnson, S. (1997). Diabetes self-management: Self-reported recommendations and patterns in a large population. Diabetes Care, 20, 568576.

Rutten, G. E. H. M., De Grauw, W. J. C., Nijpels, G., Houwelings, S. T., Van de Laar, F. A., Bilo, H. J., ... Janssen, P. G. H. (2013). NHG-standaard diabetes mellitus type 2 (derde herziening). Huisarts en Wetenschap, 56, 512-525.

Searle, A., Wetherell, M. A., Campbell, R., Dayan, C., Weinman, J., \& Vedhara, K. (2008). Do patients' beliefs about type 2 diabetes differ in accordance with complications: An investiga- tion into diabetic foot ulceration and retinopathy. International Journal of Behavioral Medicine, 15, 173-179.

Skinner, T. C., Carey, M. E., Cradock, S., Dallosso, H. M., Daly, H., Davies, M. J., ... on behalf of the DESMOND Collaborative. (2011). Comparison of illness representations dimensions and illness representation clusters in predicting outcomes in the first years following diagnosis of type 2 diabetes: Results from the DESMOND trial. Psychology \& Health, 26, 321-335.

Skinner, T. C., Khunti, K., Carey, M. E., Dallosso, H., Heller, S., \& Davies, M. J. (2014). Stabil- ity and predictive utility, over 3 years, of the illness beliefs of individuals recently diagnosed with type 2 diabetes mellitus. Diabetic Medicine, 31, 1260-1263.

Thoolen, B., De Ridder, D., Bensing, J., Gorter, K., \& Rutten, G. (2008). No worries, no impact? A systematic review of emotional, cognitive, and behavioural responses to the diagnosis of type 2 diabetes. Health Psychology Review, 2, 6593.

Thorne, S., Paterson, B., \& Russel, C. (2003). The structure of everyday self-care decision making in chronic illness. Qualitative Health Research, 13, 1337-1352.

Toobert, D. J., Hampson, S. E., \& Glasgow, R. E. (2000). The summary of diabetes self-care activities measure: Results from 7 studies and a revised scale. Diabetes Care, 23, 943-950. 
Puffelen, A.L. van, Heijmans, M.J.W.M., Rijken, M., Rutten, G.E.H.M., Nijpels, G., Schellevis, F.G. Illness perceptions and self-care behaviours in the first years of living with type 2 diabetes: does the presence of complications matter? Psychology \& Health: 2015, 30(11), 1274-1287

\section{TABLES}

Table 1. Demographic and illness-related characteristics of the participating T2DM patients, total and by the presence of complications.

\begin{tabular}{lcccc}
\hline & & \multicolumn{3}{c}{ Complications } \\
& Total $(n=192)$ & Present $(n=42)$ & Absent $(n=145)$ & $p$ \\
\hline Gender: male (\%) & 55.7 & 50.0 & 55.9 & .50 \\
Age (years; mean (SD)) & $64.3(10.0)$ & $66.2(10.0)$ & $63.6(10.0)$ & .14 \\
Educational level (\%) & & & & .50 \\
Low & 29.0 & 33.3 & 28.0 & \\
Middle & 47.9 & 50.0 & 46.9 & \\
High & 23.2 & 16.7 & 25.2 & \\
Married/cohabiting(\%) & 75.3 & 76.2 & 74.8 & .86 \\
Diabetes duration (years; mean (SD)) & $2.3(.7)$ & $2.6(.8)$ & $2.3(.7)$ & .02 \\
Treatment: pharmacological (\%) & 68.4 & 78.6 & 65.5 & .11 \\
Diabetes-related complications: present (\%) & 22.5 & 100 & 0 & - \\
Comorbid conditions: present (\%) & 66.3 & 82.1 & 62.1 & .02 \\
\hline
\end{tabular}

Table 2. Illness perceptions of T2DM patients, total and by the presence of complications (mean (SD)).

\begin{tabular}{|c|c|c|c|c|c|}
\hline & \multicolumn{3}{|c|}{ Complications } & \multirow[b]{2}{*}{$t$} & \multirow[b]{2}{*}{$p$} \\
\hline & Total $(n=192)$ & Present $(n=42)$ & Absent $(n=145)$ & & \\
\hline Identity (0-14) & $.63(1.37)$ & $1.21(2.03)$ & $.48(1.07)$ & 2.27 & .03 \\
\hline Timeline: chronic $(1-5)$ & $3.84(.76)$ & $3.91(.63)$ & $3.81(.80)$ & .72 & .47 \\
\hline Timeline: cyclical (1-5) & $2.36(.81)$ & $2.80(.81)$ & $2.23(.77)$ & 4.07 & $<.001$ \\
\hline Consequences $(1-5)$ & $2.49(.67)$ & $2.74(.82)$ & $2.42(.60)$ & 2.34 & .02 \\
\hline Personal control $(1-5)$ & $3.79(.59)$ & $3.55(.57)$ & $3.86(.58)$ & 3.12 & $<.01$ \\
\hline Treatment control $(1-5)$ & $3.78(.48)$ & $3.63(.48)$ & $3.83(.47)$ & 2.33 & .02 \\
\hline Illness coherence $(1-5)$ & $3.42(.75)$ & $3.33(.79)$ & $3.45(.75)$ & .87 & .39 \\
\hline Emotional representations $(1-5)$ & $2.17(.64)$ & $2.36(.78)$ & $2.12(.59)$ & 2.13 & .04 \\
\hline Cause: psychological factors $(1-5)$ & $2.20(.77)$ & $2.38(.80)$ & $2.16(.77)$ & 1.56 & .12 \\
\hline Cause: own behaviour $(1-5)$ & $2.49(.73)$ & $2.47(.63)$ & $2.49(.76)$ & .12 & .91 \\
\hline Cause: bad luck (1-5) & $2.66(1.16)$ & $2.67(1.15)$ & $2.65(1.18)$ & .08 & .94 \\
\hline
\end{tabular}

Table 3. Self-care behaviours performed during the previous week by T2DM patients, total and by presence of complications (mean number of days (SD)).

\begin{tabular}{lcccrcc}
\hline & & \multicolumn{2}{c}{ Complications } & & \\
\cline { 3 - 4 } & Total $(n=192)$ & Present $(n=42)$ & Absent $(n=145)$ & $t / X^{2}$ & $p$ \\
\hline Exercise (0-7) & $4.44(1.89)$ & $4.85(1.65)$ & $4.33(1.96)$ & 1.50 & .14 \\
Foot care (0-7) & $1.22(1.89)$ & $2.37(2.36)$ & $.85(1.49)$ & 3.81 & $<.001$ \\
Diet: general (0-7) & $5.16(1.67)$ & $5.33(1.51)$ & $5.15(1.69)$ & .60 & .55 \\
Diet: fruit/vegetables (0-7) & $5.36(1.96)$ & $5.65(1.83)$ & $5.27(2.01)$ & 1.04 & .30 \\
Diet: low-fat (0-7) & $4.80(2.13)$ & $4.61(2.02)$ & $4.92(2.11)$ & .83 & .41 \\
Non-smoking (\%) & 81.9 & 79.5 & 81.9 & .12 & .73 \\
\hline
\end{tabular}


Table 4. Independent associations between illness perceptions and self-care behaviour and the role of complications; regression coefficients, odds ratios and explained variance $(N=192)$.

\begin{tabular}{|c|c|c|c|c|c|c|c|c|c|c|c|c|c|c|c|c|c|c|}
\hline & \multicolumn{3}{|c|}{ Exercise } & \multicolumn{3}{|c|}{ Foot care } & \multicolumn{3}{|c|}{ Diet (general) } & \multicolumn{3}{|c|}{ Diet (fruit/veg.) } & \multicolumn{3}{|c|}{ Diet (low-fat) } & \multicolumn{3}{|c|}{ Non-smoking } \\
\hline & $\beta$ & $\beta$ & $\beta$ & $\beta$ & $\beta$ & $\beta$ & $\beta$ & $\beta$ & $\beta$ & $\beta$ & $\beta$ & $\beta$ & $\beta$ & $\beta$ & $\beta$ & OR & OR & OR \\
\hline Gender (male) & -.09 & -.12 & -.12 & .00 & .01 & .01 & -.11 & -.14 & -.14 & -.14 & -.10 & -.10 & .05 & .01 & .01 & .64 & .72 & .69 \\
\hline Age & .03 & .07 & .03 & .03 & .06 & .03 & .01 & .09 & .08 & .15 & .15 & .14 & .12 & .14 & .15 & 1.01 & 1.01 & 1.00 \\
\hline $\begin{array}{l}\text { Treatment } \\
\text { (pharmacol.) }\end{array}$ & -.03 & -.02 & -.05 & .09 & .06 & .03 & -.05 & -.07 & -.08 & -.05 & -.07 & -.08 & -.02 & -.02 & -.01 & .89 & .68 & .62 \\
\hline $\begin{array}{l}\text { Comorbidity } \\
\text { (present) }\end{array}$ & -.14 & -.12 & -.15 & .02 & -.01 & -.03 & -.10 & -.09 & -.10 & .05 & .05 & .05 & .13 & .14 & .15 & .77 & .79 & .76 \\
\hline Diabetes duration & -.02 & -.02 & -.08 & .05 & .03 & -.04 & -.11 & -.13 & -.16 & -.08 & -.08 & -.10 & -.04 & -.04 & -.02 & $.55 *$ & $.55^{*}$ & $.48^{*}$ \\
\hline Identity & & .00 & -.04 & & .14 & .12 & & .08 & .07 & & -.06 & -.06 & & .11 & .12 & & .96 & .93 \\
\hline Timeline: chronic & & -.04 & -.04 & & $.19 *$ & $.18^{*}$ & & -.09 & -.08 & & -.04 & -.04 & & .02 & .02 & & .83 & .83 \\
\hline Timeline: cyclical & & .02 & -.05 & & $.23 *$ & .16 & & .04 & .01 & & .03 & .00 & & .11 & .13 & & .93 & .87 \\
\hline Consequences & & -.06 & -.08 & & -.10 & -.12 & & .04 & .03 & & -.04 & -.04 & & -.12 & -.11 & & .74 & .74 \\
\hline Personal control & & .18 & $.21 *$ & & .02 & .05 & & .18 & $.20 *$ & & .10 & .11 & & .09 & .08 & & 1.06 & 1.10 \\
\hline Treatment control & & .12 & .13 & & .05 & .06 & & .17 & .17 & & .09 & .10 & & -.16 & -.16 & & .82 & .87 \\
\hline Illness coherence & & -.13 & -.16 & & -.04 & -.07 & & .02 & .00 & & -.03 & -.04 & & .02 & .03 & & 1.41 & 1.40 \\
\hline $\begin{array}{l}\text { Emotional } \\
\text { represent }\end{array}$ & & -.08 & -.07 & & .09 & .10 & & .04 & .05 & & .04 & .04 & & -.16 & -.16 & & .99 & .97 \\
\hline $\begin{array}{l}\text { Cause: } \\
\text { psychological }\end{array}$ & & -.04 & -.05 & & -.03 & -.05 & & -.10 & -.10 & & .21 & .21 & & -.19 & -.18 & & 1.08 & 1.03 \\
\hline $\begin{array}{l}\text { Cause: own } \\
\text { behaviour }\end{array}$ & & -.02 & -.01 & & -.03 & -.01 & & -.13 & -.13 & & $-.42 * *$ & $-.41 * *$ & & .22 & .21 & & $.37^{*}$ & $.38^{*}$ \\
\hline Cause: bad luck & & .02 & .04 & & -.07 & -.05 & & .06 & .07 & & .07 & .08 & & .04 & .03 & & .93 & .94 \\
\hline $\begin{array}{l}\text { Complications } \\
\text { (present) }\end{array}$ & & & $.29 * *$ & & & $.30 * *$ & & & .15 & & & .10 & & & -.09 & & & 2.23 \\
\hline Adjusted $R^{2}$ & .00 & .00 & .07 & .00 & .03 & $.10^{*}$ & .00 & .04 & .05 & .01 & .06 & .06 & .00 & .01 & .01 & & & \\
\hline Nagelkerke $R$ & & & & & & & & & & & & & & & & .07 & .15 & .15 \\
\hline
\end{tabular}

*Significant at .05 level.

**Significant at .01 level. 